\title{
Optimal clamping time in meatotomy procedure for children with meatal stenosis: Experience with 120 cases
}

\author{
Mehdi Shirazi ${ }^{1,2}$, Umayir Chowdhury ${ }^{3}$, Faisal Ahmed ${ }^{4 *}$, Mohammad-Bagher Rajabalian ${ }^{1}$, \\ Hossein-Ali Nikbakht ${ }^{5}$, Khalil Al-Naggar ${ }^{4}$, Ebrahim Al-Shami ${ }^{4}$ \\ ${ }^{1}$ Department of Urology, Shiraz University of Medical Sciences, Shiraz, Iran; \\ ${ }^{2}$ Histomorphomettery and Stereology Research Center, Shiraz University of Medical Sciences, Shiraz, Iran; \\ 3 School of Medicine, Shiraz University of Medical Sciences, Shiraz, Iran; \\ ${ }^{4}$ Urology Research Center, Al-Thora General Hospital, Department of Urology, Ibb University of Medical Since, Ibb, Yemen; \\ ${ }^{5}$ Social Determinates of Health Research Center, Department of Biostatics and Epidemiology, Faculty of Medicine, \\ Babol University of Medical Sciences, Babol, Iran.
}

\begin{abstract}
Summary $\quad$ Objective: During meatotomy procedure for children with meatal stenosis (MS), a straight clamp used as a hemostat on the ventrum of the meatus before incised with scissors for clamping and holding bleeding from the site of operation. The aim of this study was to evaluate the optimum clamping time for meatotomy in children with MS. Materials and methods: All the patients with MS between 2014 to 2019 were enrolled in this retrospective study. Patients with uncircumcised penis, traumatic catheterization, any kind of penile abnormality such as hypospadias or penile curvature, and active urinary tract infection (UTI) were excluded. The indication of meatotomy was a pinpoint meatus that develops with dorsal or lateral deflection of the urinary stream and high-velocity urine flow. During meatotomy procedure, clamping time was examined in different groups such as 2, 3, and 4 minutes. The main symptoms of presentation and ultrasonography (US) findings were recorded and compared between groups. To assess the optimum time clamping, postoperative bleeding was noted carefully in all groups. The success rate was recorded at onemonth postoperative follow-up in the clinic.

Results: Of the 120 patients with MS who underwent a meatotomy procedure, there were 40 (33.3\%) participants in each group. The main symptoms were painful urination and urine stream deviation that represented in 54 (46\%) patients. Bladder wall thickness was the main pre-operation finding in the US which was observed in 67 (55.8\%) patients. In comparison between the groups related to clamping time, bleeding was observed and required suturing when clamping was applied for 2 minutes in 4 (3.3\%) patients ( $p=0.016)$. With a minimum follow-up of 12 months, no recurrent meatal stenosis was reported. Conclusions: Clamping time for more than 2 minutes may prevent bleeding during and after meatotomy.
\end{abstract}

KEY wORDS: Bleeding; Clamping time; Meatal stenosis; Meatotomy.

Submitted 10 March 2021; Accepted 2 May 2021

\section{INTRODUCTION}

One of the most common complications after circumcision is meatal stenosis (MS) which occurs in approximately $9 \%-10 \%$ of patients (1). MS is defined as narrowing of the opening of the external urethral meatus less than $2 \mathrm{~mm}$ (2). Prolonged exposure of the delicate mea- tus to an irritating environment of the diaper (diaper dermatitis) is the common pathologic cause of this condition (3). Post circumcision meatal stenosis may also result from ischemia of the meatal mucosa secondary to damage to the frenular artery (2).

Patients with MS can present with symptoms of voiding difficulties, such as pinpoint meatus, difficulty to aim or an upward and forceful urinary stream, dysuria, urgency, frequent and prolonged urination. Therefore, untreated MS can lead to urinary tract infections and kidney problems (1). To confirm the diagnosis, detailed history and physical exam including observation of urination and examining the urethral opening are evaluated carefully (1). Regarding the methods of circumcision, it was hypothesized by Graves that MS is more common after a Plastibell circumcision (2).

Meatotomy is a simple common procedure for the treatment of MS that can be performed with minimal instrumentation and in this procedure, the ventrum of the meatus is crushed with a straight clamp and then the crushed ventral tissue is incised sharply with fine-tipped scissors (1). Side effects of meatotomy are bleeding during or after meatotomy, mild discomfort for the first day following the operation, recurrence, pain, dysuria, and dysuria induced urinary retention, infection, edema, and spraying of the urine stream as a consequence of edema for a while (2-4). Among all the complications mentioned above, bleeding could be a matter of utmost importance in which clamping time might have played a key role. The clamping times recommended in previous literature were between 60 seconds to 3 minutes $(1,4-7)$.

In these circumstances, we could not find any study that shows us if there is any correlation between clamping time and bleeding during and after meatotomy procedure. Therefore, we conducted a study to find out the optimal clamping time in meatotomy.

\section{MATERIALS AND METHODS}

Study design

The Ethics Committee of Shiraz University of Medical Sciences approved the protocol of the study (IR.SUMS.MED.REC. 
1397.507). This is a retrospective study, which included all the patients with MS during five years from July 2014 to September 2019, which evaluated by one single pediatric urologist were enrolled in this study. Patients with uncircumcised penis, traumatic catheterization, prior penile surgery, any penile abnormality such as hypospadias or penile curvature, and active urinary tract infection (UTI) were excluded. Written informed consent was taken from the patient's parents before the operation and the benefit and risk of this procedure were explained. The indication of meatotomy was a pinpoint meatus that develops with dorsal or lateral deflection of the urinary stream and highvelocity urine flow (8).

During meatotomy procedure, clamping time was checked in different groups such as 2, 3, and 4 minutes. The demographic characteristics such as skin eruption around meatus, age, history of allergy, age of circumcision, US finding, main symptoms, and Quality of voiding after operation were recorded and compared between groups. to assess the optimum time clamping, postoperative bleeding was noted carefully in all groups. The success rate was recorded at one-month postoperative follow-up in the clinic.

\section{Surgical procedure}

All procedures were done under general anesthesia in the supine position. Minimal skin prep and drape of the genitalia were done with Iodopovidone. Then one jaw of a well-lubricated mosquito hemostat was introduced into the ventral aspect of the urethral meatus to a depth of approximately $2-3 \mathrm{~mm}$, depending on the severity of stenosis and patient age. Then, by closing the hemostat, the ventral tissue was crushed. Clamping time was checked in different groups such as 2, 3, and 4 minutes. Then crushed tissue was divided gently with a fine-tipped scissor. A small amount of antibiotic was placed over the raw edges (8). The meatotomy site was shown to the parents and the surgeon demonstrated how to open the meatus two times daily to apply Dexpanthenol-Chlorhexidine cream for 2 weeks (9).

\section{Surgical outcome}

During the procedure bleeding of the surgical site was recorded by a pediatric urologist and if occurred, firstly pressure on the edges performed and if not stopped then it would be sutured with 6/0 Polyglactin suture material. Quality of voiding and symptoms were asked from the patient's family and meatal opening using visual inspection was recorded in the outpatient clinic one month after the operation.

\section{Statistical analysis}

The mean \pm SD and median, Inter-Quartile Range (IQR), described the quantitative variables, and frequency (percent) was used for qualitative variables. We assessed the normality as the assumption of the variables in the study by the Kolmogorov-Smirnov test.

Table 1.

Table 2.
When data were non-normally distributed, the non-parametric test was used. The Chi-square test was used to assess a probable statistically significant difference between qualitative variables for limitations on the observed frequency of Fisher's exact test. ANOVA was applied to compare the difference of means between more than two different levels or the non-parametric Krusal Wallis test was applied.

The collected data were analyzed by SPSS version 20 . A P-value less than 0.05 was considered statistically significant.

\section{RESULT}

The patient's characteristics were summarized in Table 1 . Of the 120 patients diagnosed with MS were enrolled in this study. The mean patient age was $50.88 \pm 29.73$ months. The time between circumcisions to meatotomy procedure was $49.5 \pm 30.84$ months. Skin eruption around meatus was found in $6(5.0 \%)$ patients. All coagulation tests (PT, PTT, INR, and Platelet) were normal in all patients. Related to symptoms of MS, the main symptoms were painful urination and urine stream deviation which represented in 54 (46\%) patients. Other symptoms were summarized in Table 2. Bladder wall thickness was the main pre-operation finding in US which represented in 67 (55.8\%) patients. US finding were summarized in Table 2. Voiding quality at one month after operation excellent in $79(65.8 \%)$ patients, improved in $38(31.7 \%)$ patients, and partially improved in $3(2.5 \%)$ of patients and at long term (12 months) follow-up remained without symptoms.

In comparison between the groups related to clamping

Main characteristics of patients.

\begin{tabular}{|c|c|c|c|c|c|}
\hline$P$ value & $\begin{array}{c}4 \text { min clamping } \\
\text { time (40) }\end{array}$ & $\begin{array}{c}3 \text { min clamping } \\
\text { time (40) }\end{array}$ & $\begin{array}{c}2 \text { min clamping } \\
\text { time (40) }\end{array}$ & $\begin{array}{c}\text { Total number } \\
120\end{array}$ & Variables \\
\hline$\overline{0.031}$ & $60.07 \pm 33.74$ & $49.85 \pm 30.76$ & $42.73 \pm 21.39$ & $50.88 \pm 29.73$ & Age (months) ${ }^{\mathrm{a}}$ \\
\hline 1.000 & $2(33.3)$ & $2(33.3)$ & $2(33.3)$ & $6(5.0)$ & Skin eruption around meatus ${ }^{b}$ \\
\hline 0.265 & $2(14.2)$ & $6(42.9)$ & $6(42.9)$ & $14(11.7)$ & History of allergy ${ }^{b}$ \\
\hline 0.19 & $2.47 \pm 2.35$ & $3.51 \pm 5.87$ & $3.39 \pm 3.78$ & $3.12 \pm 4.24$ & Age at circumcision (months) ${ }^{c}$ \\
\hline 0.016 & $0(0)$ & $0(0)$ & $4(100)$ & $4(3.3)$ & Bleeding ${ }^{b}$ \\
\hline
\end{tabular}

US finding and symptoms of patients.

\begin{tabular}{|c|c|c|c|c|l|}
\hline P value & 4 min clamping & 3 min clamping & 2 min clamping & Total 120 & Variables \\
\hline \multirow{3}{*}{0.010} & $18(33.3)$ & $18(33.3)$ & $18(33.3)$ & $54(46)$ & Painful urination and urine stream deviation \\
& $9(37.5)$ & $4(16.7)$ & $11(45.8)$ & $24(20)$ & Stream narrowing and infrequent voiding \\
& $10(62.5)$ & $5(31.3)$ & $1(6.3)$ & $16(13.3)$ & Urge incontinence and retention \\
& $2(16.7)$ & $5(41.7)$ & $5(41.7)$ & $12(10)$ & No symptoms \\
& $0(0.0)$ & $8(61.5)$ & $5(38.5)$ & $13(10.7)$ & Prolonged time of micturition \\
\hline \multirow{3}{*}{0.877} & $23(34.3)$ & $21(31.3)$ & $23(34.3)$ & $67(55.8)$ & Bladder wall thickness \\
& $5(31.3)$ & $6(37.5)$ & $5(31.3)$ & $16(13.4)$ & Unilateral mild hydronephrosis \\
& $2(50)$ & $2(50)$ & $0(0)$ & $4(3.3)$ & Bilateral mild hydronephrosis \\
& $10(30.3)$ & $11(33.3)$ & $12(36.4)$ & $33(27.5)$ & Normal US finding \\
\hline
\end{tabular}

US, Utrasonography. P. Pvalues of $<0.05$ were considered siginificant. ${ }^{b}$ Data was presented as $n(\%)$. 
Table 3.

Summary of published studies with clamping time, type of anesthesia and complications.

\begin{tabular}{|l|c|c|c|l|}
\hline Study & $\begin{array}{c}\text { Patients } \\
\text { number }\end{array}$ & $\begin{array}{c}\text { Type of } \\
\text { anesthesia }\end{array}$ & $\begin{array}{c}\text { Clamping time } \\
\text { (minutes) }\end{array}$ & Complication \\
\hline Neheman (9) & 25 & General & 2 & Mild meatal stenosis in 3 patients \\
\hline Fronczak (8) & 55 & Topical & - & Repeated meatotomy in 3 patients \\
\hline Wang (1) & - & General & 1 & No complication \\
\hline Priyadarshi (12) & 48 & Local & $2-3$ & Penile numbness in 2 patients for 1 day \\
\hline Ben-Meir (3) & 76 & General/Local & 1 & Bleeding in 3 patients, Lannngospasm in 2 patients \\
\hline Lane (5) & - & - & 3 & No complication \\
\hline Cubillos (11) & 85 & General & 1 & No complication \\
\hline Roth (7) & 100 & Local & 5 & No complication \\
\hline Elkhafifi (13) & 86 & General & $1-2$ & No complication \\
\hline
\end{tabular}

The clamping times recommended in previous literature were between 60 seconds to 3 minutes Table 3 shows the earlier published study with clamping time and complications (1, 3-9, 11-13).

David Ben-Meir et al. noted that bleeding occurred in two patients who received sedation and general anesthesia and one patient who received penile block and general anesthesia. Clamping time in all patients was one minute. However, children who had bleeding had various degrees of skin reaction (edema and blanching) and they concluded that blanching may have increased the risk of bleeding due to fragility of tissue or the difficulty in cutting precisely through the crush line made by the hemostat (3).

time, there was no statistically significant difference among the groups in terms of skin eruption around meatus, history of allergy, circumcision method, US finding, voiding quality after one month of operation, and meatal width. However, the mean age in 2 minutes group was younger than another group $(p=0.031)$.

Significant bleeding was observed and required suturing when clamping time was for 2 minutes in 4 (3.3\%) patients $(p=0.016)$. Painful urination and urine stream deviation was the main symptoms in all groups $(p=0.010)$. Besides, with a minimum follow-up of 12 months, no recurrent MS was reported.

\section{Discussion}

The main cause of MS is circumcision. It is usually common in Jews and Muslims and this problem is highly detected in Israel, where most boys are ritually circumcised in early infancy (3).

Different methods are approved to perform neonatal circumcision but three techniques are used regularly: the Mogen clamp, the Gomco clamp, and the Plastibell Device. Previously published articles revealed that neonatal circumcision using Plastibell Device with intact frenulum technique decreases the rate of delayed MS (10), whatever in our study frequency of MS between the Sleeve and the Plastibell methods was not statically significant between groups.

Sever MS is a late complication that is mainly noticed 12 years after circumcision which is simply treated by meatotomy.

Meatotomy is a simple common procedure for the treatment of MS that can be performed with minimal instrumentation and in this procedure, the ventrum of the meatus is crushed with a straight clamp and then the crushed ventral tissue is incised sharply with fine-tipped scissors (1). Side effects of meatotomy are bleeding during or after the procedure, mild discomfort for the first day following the operation, recurrence, pain, dysuria, dysuria induced urinary retention, infection, edema, and spraying of the urine stream as a consequence of edema for a while (2-4). Among all the complications mentioned above, bleeding could be a matter of utmost importance in which clamping time might have played a key role.
James et al. recommended that clamping for three minutes reduces bleeding and facilitates placement of sutures (5). Our result was similar to the previous studies and showed significant bleeding was observed and required suturing when the clamping time was for 2 minutes.

Parisa and associates evaluated 87 children with MS and they concluded that decreased urine stream is a common symptom which was seen among 54\% of patients with MS. Besides, increased bladder wall thickness was the most common finding in Ultrasonography (US) which was revealed in $82 \%$ of the patients (14). Our result was similar to the previous study.

David et al. assessed the quality of void at 24 hours and 1 month after meatotomy (3). In agreement with this study, we also evaluated the quality of voiding one month after surgery, and in our opinion; this time was enough for the meatus to heal.

Local anesthesia was highly recommended in recent studies. However, it is important to mention that restlessness and anxiety, especially in the patient less than 4 years, is the main limitation for local anesthesia in meatotomy procedure. Besides, meatoplasty under general anesthesia had a lower recurrence rate compared to meatotomy under local anesthesia $(0.2 \%$ vs $3.5 \%)(3,6,8)$.

Although in some parts of the world like our country (Iran) the cost of a meatotomy under GA and meatotomy under local anesthesia might be roughly the same (8).

Mahmoudi et al. mentioned that US might not be necessary for every patient with MS after meatotomy.

However, it is recommended to perform the radiologic study in cases of specific symptom continuation. We agree with him and we also did not perform any US after meatotomy procedure unless specific symptom was found in post-surgical follow-up (15).

The current study had some limitations. Firstly, the small size number of patients. Secondly, the lack of longterm follow-up.

Thirdly, the surgeon's propensity to operate could be biased by their propensity to diagnosis MS and this could affect the rates cited.

Fourthly, it is hard to assess the quantity of bleeding by laboratory investigation and the amount of bleeding and the need for suturing was assessed by pediatric urologist. Finally, it was a retrospective analysis. 


\section{Conclusions}

The main symptoms of MS are painful urination and urine stream deviation. Additionally, clamping time for more than 2 minutes may prevent bleeding during and after meatotomy.

However, this observation needs to be validated in a large number cohort study with long-term post-procedural follow-up.

\section{ACKNOWLEDGMENTS}

The authors would like to thank Shiraz University of Medical Sciences, Shiraz, Iran and, also the Center for Development of Clinical Research of Nemazee Hospital and Dr. Nasrin Shokrpour for editorial assistance.

\section{REFERENCES}

1. Wang M-H. Surgical management of meatal stenosis with meatoplasty. J Vis Exp. 2010.

2. Van Howe RS. Incidence of meatal stenosis following neonatal circumcision in a primary care setting. Clin Pediatr. 2006; 45:49-54.

3. Ben-Meir D, Livne PM, Feigin E, et al. Meatotomy using local anesthesia and sedation or general anesthesia with or without penile block in children: a prospective randomized study. J Urol. 2011; 185:654-7.

4. Ajemian EP, Lichtwardt JR, Gonzalez J, et al. Technique for avoiding stricture following urethral meatotomy. J Urol. 1961; 86:340-2.
5. Lane JW. Modified technique of urethral meatotomy in males. Urology. 1986; 27:170.

6. Cartwright PC, Snow BW, McNees DC. Urethral meatotomy in the office using topical EMLA cream for anesthesia. J Urol. 1996; 156:857-9.

7. Roth RB. Office Urology. J Postgrad Med. 1971; 49:109-13.

8. Fronczak C, Villanueva C. Clinic meatotomy under topical anesthesia.J Pediatr Urol. 2017; 13:499. e1-. e3.

9. Neheman A, Rappaport YH, Darawsha AE, et al. Uroflowmetry before and after meatotomy in boys with symptomatic meatal stenosis following neonatal circumcision-A long-term prospective study. Urology. 2019; 125:191-5.

10. Karami H, Abedinzadeh M, Moslemi MK. Assessment of meatal stenosis in neonates undergoing circumcision using Plastibell Device with two different techniques. Res Rep Urol. 2018; 10:113.

11. Cubillos J, George A, Gitlin J, et al. Tailored sutureless meatoplasty: A new technique for correcting meatal stenosis. J Pediatr Urol. 2012; 8:92-6.

12. Priyadarshi V, Puri A, Singh JP, et al. Meatotomy using topical anesthesia: a painless option. Urol Ann. 2015; 7:67.

13. Elkhafifi MH. Presentation and management of postcircumcision meatal stenosis at Hawari Center, Benghazi, Libya: A clinical review of 86 cases. Libyan Int Med Univ J. 2019; 4:69.

14. Saeedi P, Ahmadnia H, Akhavan Rezayat A. Evaluation of the Effect of Meatal Stenosis on the Urinary Tract by using Ultrasonography. Urol J. 2017; 14:3071-4.

15. Mahmoudi $H$. Evaluation of meatal stenosis following neonatal circumcision. Urol J. 2005; 2:86-8.

\author{
Correspondence \\ Mehdi Shirazi, MD \\ shirazim@sums.ac.ir \\ Umayir Chowdhury, MD \\ umayir09@gmail.com \\ Mohammad-Bagher Rajabalian, MD \\ mj.rajabalian@yahoo.com \\ Urology Office, Faghihi Hospital, Zand Blvd., Shiraz (Iran) \\ Faisal Ahmed, MD (Corresponding Author) \\ fmaaa2006@yahoo.com \\ Urology Office, Al-Thora General Hospital, Alodine street, Ibb (Yemen) \\ Hossein-Ali Nikbakht, MD \\ ep.nikbakht@gmail.com \\ Social Determinates of Health Research Center, Babol University \\ of Medical Sciences, Babol (Iran) \\ Khalil Al-Naggar, MD \\ alnajjarkh1234@gmail.com \\ Ebrahim Al-Shami, MD \\ alshami_ebrahim@yahoo.com \\ Urology Office, Althora General Hospital, Alodine street, Ibb (Yemen)
}

